\title{
A densification mechanism to model the mechanical effect of methane
} hydrates in sandy sediments

\author{
M. De La Fuente ${ }^{1,2}$, J. Vaunat ${ }^{3}$, H. Marín-Moreno ${ }^{1}$ \\ ${ }^{1}$ National Oceanography Centre, University of Southampton Waterfront Campus, European Way, Southampton \\ SO14 3ZH, UK. \\ ${ }^{2}$ Ocean and Earth Science, University of Southampton, European Way, Southampton SO14 3ZH, UK \\ ${ }^{3}$ Department of Civil and Environmental Engineering, Universitat Politècnica de Catalunya, Barcelona, Spain.
}

\section{SUMMARY}

Recent pore-scale observations and geomechanical investigations suggest the lack of true cohesion in methane hydrate-bearing sediments (MHBS) and propose that their mechanical behavior is governed by kinematic constrictions at pore-scale. This paper presents a constitutive model for MHBS, which does not rely on physical bonding between hydrate crystals and sediment grains, but on the densification effect that pore invasion with hydrate has on the sediment mechanical properties. The Hydrate-CASM extends the critical state model Clay and Sand Model (CASM) by implementing the subloading surface model and introducing the densification mechanism. The model suggests that the decrease of the sediment available void volume during hydrate formation stiffens its structure and has a similar mechanical effect as the increase of sediment density. In particular, the model attributes stress-strain changes observed in MHBS to the variations in sediment available void volume with hydrate saturation and its consequent effect on isotropic yield stress and swelling line slope. The model performance is examined against published experimental data from drained triaxial tests performed at different confining stress and with distinct hydrate saturation and morphology. Overall, the simulations capture the influence of hydrate saturation in both the magnitude and trend of the stiffness, shear strength and volumetric response of synthetic MHBS. The results are validated against those obtained from previous mechanical models for MHBS that examine the same experimental data. The Hydrate-CASM performs similarly to previous models but its formulation only requires one hydrate-related empirical parameter to express changes in the sediment elastic stiffness with hydrate saturation.

KEY WORDS: methane hydrate-bearing sediments; mechanical behavior; densification mechanism; Hydrate-CASM; constitutive modeling. 
Methane hydrates have drawn international interest as an alternative energy resource to conventional fossil fuels [1-5], and as a major hazard for offshore drilling and gas production operations [6-8], global climate change [9-12] and seafloor instability [13-15]. Quantitative evaluation of the resource potential of gas hydrate reservoirs and of their response to natural and/or human-induced changes in pressure and temperature (P-T) conditions, requires precise knowledge of the hydrate phase change phenomenon and of its effect on the mechanical stability of the reservoir. Due to the operational complexity at preserving the in-situ P-T conditions during MHBS recovery, the mechanical properties of these sediments are generally investigated through geophysical techniques [16-18] and geotechnical testing of synthetic sediments [19-21]. Both geophysical and geotechnical data show that the stiffness, strength, and dilatancy of MHBS tend to increase with increasing hydrate saturation [22, 23]. They also evidence that their mechanical and hydraulic properties drastically change during hydrate dissociation, which may compromise the mechanical stability of the sediment. Thus, hydrate dissociation is likely to trigger small to large-scale deformations in the seabed, including sediment collapse [24] and sliding [25-27]. As a result, dissociation may also induce damage of preexisting offshore infrastructures [28].

Several mechanical models developed for MHBS assume that the increase of strength, stiffness and dilatancy observed in these sediments is mainly governed by bonding or cementation between the hydrate crystal and the sediment grains (Table 1). However, recent pore-scale observations [29-31] and geomechanical investigations [32-34] evidence the lack of true cohesion in MHBS and suggest that the mechanical response of these sediments may not necessarily be governed by sediment bonding/cementation, but rather to kinematic constrictions at pore/grain scale during shearing. In this paper, we develop a new mechanical constitutive model that does not consider hydrate-bonding effects in its formulation but assumes that the reduction of sediment available void volume and the increase of sediment elastic stiffness during pore invasion with hydrate can explain the greater mechanical properties observed in MHBS

The elasto-plastic model Hydrate-CASM extends the formulation of the unified critical state constitutive model CASM [46] by implementing the subloading surface model [47] and introducing the densification mechanism. The subloading surface, which has been successfully 
used in previous mechanical models for MHBS [39, 40, 44, 48], allows capturing irrecoverable plastic strains inside the yield surface. The densification mechanism suggests that the decrease of the available void volume of the host sediment during hydrate formation stiffens its structure and has a similar mechanical effect as the increase of the sediment density. In particular, the densification mechanism attributes the stress-strain changes observed in MHBS to variations in sediment available void volume with hydrate saturation and its consequent effect on isotropic yield stress and swelling line slope.

The Hydrate-CASM is applied here to robust and well-described published experimental data $[19,21]$ that cover the most relevant conditions related to MHBS behavior, including a wide range of hydrate saturations, several hydrate morphologies and confinement stress. These data have also been used in the calibration of previous mechanical models developed for MHBS [e.g., 39, 40, 48-50], which give us the opportunity to compare and validate our results. The model performance is found satisfactory over a wide range of test conditions and evidence the capability of the Hydrate-CASM model at capturing both the trend and magnitude of the stressstrain and the volumetric response of synthetic MHBS. In addition, the good matching of our results with the outputs obtained from previous mechanical models for MHBS evidences that the experimental data examined in this paper can be simply reproduced by (i) considering the mechanical effect of the reduction of sediment available void volume due to pore invasion with hydrate and (ii) modifying the sediment elastic stiffness according to hydrate saturation. Our results also show that accounting for the different initial void ratios of the set of host specimens used to produce cementing and pore-filling MHBS allows capturing the experimental data without using any empirical parameters related to the hydrate morphology.

\section{CASM MODEL}

The Hydrate-CASM extends the formulation of the constitutive model CASM developed by $\mathrm{Yu}$ [46]. The CASM model is selected here because of its simplicity and flexibility in describing the shape of the yield surface as well as its proven ability to predict the mechanical behavior of sand, the most likely target for the commercial exploitation of hydrates [51]. The critical state model CASM is formulated in terms of the state parameter [52] and the spacing ratio concept, and uses a non-associated flow rule, which is particularly suitable to simulate the behavior of granular sediments like those examined in this paper [53,54]. All the parameters used in the formulation are listed and defined in Table 2. 
$\xi=v+\lambda \ln \left(p^{\prime}\right)-\Gamma(1)$

The magnitude and sign of this parameter play a key role in understanding the densification mechanism introduced in this paper. The state parameter adopts positive values when the sediment void ratio is located above the critical state line (CSL) (as in loose sand; Figure 1a), and negative ones when located below it (as in dense sand; Figure 1c). Sediments with a positive value of $\xi$ and subjected to triaxial shear tend to show hardening on the $p^{\prime}-q$ stress space and contractancy as volumetric response (Figure 1b). Instead, sediments with a negative value of $\xi$ show a distinctive peak in the deviatoric stress followed by softening before the critical state is achieved, and dilatancy dominates its volumetric response (Figure 1d).

\subsection{CASM yield function}

A total of seven model parameters are required to define the original CASM formulation. Five of which $(\lambda, M, \Gamma, \kappa$ and $v)$, are the same as those in the Cam Clay model [55,56], and the two additional parameters, denoted by $n$ and $r$, are used to specify the geometrical properties of the yield function. For a general stress state, the CASM yield function is expressed as:

$f=\left(\frac{q}{M p^{\prime}}\right)^{n}+\frac{1}{\ln (r)} \ln \left(\frac{p^{\prime}}{p_{0}^{\prime}}\right)(2)$

Where $n$ governs the shape of the yield surface and $r$ controls its intersection with the critical state line. Particular combinations of $n$ and $r$ allow the intersection between the critical state line and the yield surface to not necessarily occur at the maximum deviatoric stress (Figure 2) as happens in Cam-Clay type models. This allows the CASM model to predict local peaks in the deviatoric stress on the left side of the critical state condition, feature that is widely observed in geotechnical testing of sand [57, 58]. Certain values of $n$ and $r$ can also recover the yield surface function of the standard and modified Cam-clay models [46]. 
135 Within the yield surface, the behavior is assumed isotropic and elastic, with the elastic 136 volumetric stress-strain relationship governed by the bulk modulus $K$ (Eq. 3a) and the elastic 137 shear by the shear modulus $G$ (Eq. 3b):

$138 \quad K=\frac{(1+e) p \prime}{\kappa}(3 \mathrm{a})$

$139 G=\frac{3 K(1-2 v)}{2(1+v)}(3 \mathrm{~b})$

\subsection{Stress-dilatancy relation and plastic potential}

The CASM model uses a non-associated flow rule that follows the stress-dilatancy law proposed by Rowe [59], which has been applied with success at describing the deformation of sands and granular materials [46], as well as to simulate the response of MHBS [32, 33].:

$145 \quad \frac{d \varepsilon_{v}^{p}}{d \varepsilon_{q}^{p}}=\frac{9(M-\eta)}{9+3 M-2 M \eta}(4)$

By integrating equation (4), the CASM plastic potential function is obtained as:

$g=3 M \ln \left(\frac{p^{\prime}}{\varphi}\right)+(3+2 M) \ln \left(\frac{2 q}{p^{\prime}}+3\right)+(M-3) \ln \left(3-\frac{q}{p^{\prime}}\right)(5)$

Whose expression does not depend on the hardening parameters and where $\varphi$ is a size parameter controlling the size of the plastic potential which passes through the current stress state $\left(p^{\prime}-q\right)$.

151

152

153

\subsection{Hardening parameters}

Similar to Cam-clay type models, the CASM model assumes isotropic changes in the isotropic yield stress controlled by the incremental plastic volumetric deformation, so that:

$$
d p_{0}^{\prime}=\frac{(1+e) p_{0}^{\prime}}{\lambda-\kappa} d \varepsilon_{v}^{p}(6)
$$


The Hydrate-CASM extends the formulation of the CASM model [46] by implementing the subloading surface model [47] and introducing the densification mechanism. We note that material parameters $e, v, p^{\prime}{ }_{0}$ and $\kappa$ presented in equations 1 to 5 read as $e_{a h}, v_{h}, p_{0_{h}}^{\prime}$ and $\kappa_{h}$ in the presence of hydrate within the sediment.

\subsection{Hydrate-CASM subloading function}

It is widely recognized that plastic strains can develop for stress states inside the yield surface; its interior is not a purely elastic domain. This feature results in a smooth transition between the elastic and the plastic response of soils [60, 61]. González [62] shows that the CASM yield function reproduces well the residual soil strength, but generally over-estimates the elastic strains and predicts unrealistic sharp transitions between the elastic and elastoplastic states. The subloading surface concept [47] is implemented in the present formulation to account for preyield plasticity that allows capturing a smoother transition between elastic and plastic behavior, and a more accurate volumetric response of MHBS. This model assumes the existence of a subloading surface that expands/contracts inside the general yield surface keeping its same shape. The Hydrate-CASM subloading function is derived from equation 2 as:

$f=\left(\frac{q}{M p^{\prime}}\right)^{n}+\frac{1}{\ln (r)} \ln \left(\frac{p^{\prime}}{R p_{0_{h}}^{\prime}}\right)(7)$

Where $R$ controls the size of the subloading surface (Table 2) and recovers the original CASM yield function for values equal to 1 . The evolution of $R$ is controlled by the norm of the incremental plastic strain vector and the subloading parameter $(u)$ :

$d R=-u \ln R\left|d \boldsymbol{\varepsilon}^{p}\right|(8)$

\subsubsection{Plastic strain}

The constitutive equation that characterizes an elasto-plastic material can be expressed as the following stress-strain relationship:

$$
d \boldsymbol{\sigma}^{\prime}=\boldsymbol{D}^{e} d \boldsymbol{\varepsilon}^{e}=\boldsymbol{D}^{e}\left(d \boldsymbol{\varepsilon}-d \boldsymbol{\varepsilon}^{p}\right)(9 \mathrm{a})
$$

With: 
$190 \quad \boldsymbol{D}^{e}=\left[\begin{array}{cccccc}K+\frac{4}{3} G & K-\frac{2}{3} G & K-\frac{2}{3} G & 0 & 0 & 0 \\ K-\frac{2}{3} G & K+\frac{4}{3} G & K-\frac{2}{3} G & 0 & 0 & 0 \\ K-\frac{2}{3} G & K-\frac{2}{3} G & K+\frac{4}{3} G & 0 & 0 & 0 \\ 0 & 0 & 0 & G & 0 & 0 \\ 0 & 0 & 0 & 0 & G & 0 \\ 0 & 0 & 0 & 0 & 0 & G\end{array}\right](9 \mathrm{~b})$

191

$192 d \boldsymbol{\varepsilon}^{p}=d \lambda^{p} \frac{\partial g}{\partial \sigma^{\prime}}(9 \mathrm{c})$

193

194 The elastoplastic regime is reached when the stress state lies on the Hydrate-CASM yield

195 surface. For the stress state to remain on it at any plastic loading, the consistency condition

196 must be satisfied:

197

198

$d f\left(\boldsymbol{\sigma}^{\prime}, \chi\right)=0(10)$

199 By linearizing the consistency condition, $d f$ can be rewritten as:

$200 d f=\left(\frac{\partial f}{\partial \sigma^{\prime}}\right)^{T} d \boldsymbol{\sigma}^{\prime}+\left(\frac{\partial f}{\partial \chi}\right)^{T} d \chi=0$ (11a)

201 with:

$202 \frac{\partial f}{\partial \sigma^{\prime}}=\frac{\partial f}{\partial p^{\prime}} \frac{\partial p^{\prime}}{\partial \sigma^{\prime}}+\frac{\partial f}{\partial q} \frac{\partial q}{\partial \sigma^{\prime}}(11 \mathrm{~b})$

203

$204 \frac{\partial f}{\partial \chi}=\left(\frac{\partial f}{\partial p^{\prime} 0_{h}}+\frac{\partial f}{\partial R}\right)(11 \mathrm{c})$

205 By solving equations $9 \mathrm{c}$ and 10 the plastic multiplier is classically obtained as:

$206 d \lambda^{p}=\frac{\left(\frac{\partial f}{\partial \sigma^{\prime}}\right)^{T} D^{e} d \varepsilon}{H+\left(\frac{\partial f}{\partial \sigma^{\prime}}\right)^{T} D^{e} \frac{\partial g}{\partial \sigma^{\prime}}}(12 \mathrm{a})$

207 where:

$208 \quad H=-\left(\frac{\partial f}{\partial p^{\prime} o_{h}} \frac{\partial p^{\prime} o_{h}}{\partial d \varepsilon_{v}^{p}}+\frac{\partial f}{\partial R} \frac{\partial R}{\partial\left|d \varepsilon^{p}\right|}\right) \delta^{T} \frac{\partial g}{\partial \sigma^{\prime}}(12 \mathrm{~b})$

209

$\delta^{T}=\{1,1,1,0,0,0\}(12 \mathrm{c})$ 


\subsection{Densification mechanism}

212

In nature, variations in the sediment void volume may result from two competing and interdependent processes: (i) mineral precipitation or dissolution (which compares here to hydrate formation and dissociation, respectively) and (ii) mechanical compaction or dilation under pressure [63]. In particular, mineral precipitation in pores reduces the sediment available void volume without experiencing mechanical compaction [64 and 65] and has a significant effect on its hydraulic and mechanical properties [e.g., 63, 66].

Figure 3 examines qualitatively the effect of sediment density or void ratio on the magnitude of $\xi$ and the corresponding mechanical behavior of the sediment under triaxial shear. For a reference sediment with positive $\xi$ (grey cross in Figure $3 a$ and $3 b$ ), an increase in density or a reduction of the void ratio reduces the vertical distance between the current state and the CSL (black cross in Figure 3b). Thus, during shear, the model predicts less hardening and contractancy than that observed on the reference sediment (Figure 3c). For a reference sediment with negative $\xi$ (grey cross in Figure $3 \mathrm{~d}$ and 3e), an increase in density increases the distance of the current state from the CSL (black cross in Figure 3e), and consequently, during shear, the model predicts a higher peak strength and greater dilatancy than that observed on the reference sediment (Figure 3f).

Figure 3 shows that variations in $\xi$ related to an increase in sediment density produce a similar mechanical response than those observed in sediments with increasing hydrate saturation (i.e., greater strength and dilatancy, or less contractancy, compared to the sediment without hydrate). Thus, we suggest that the occurrence of hydrate as a solid phase invading the voids of the hosting sediment may have a similar mechanical effect than the increase of the host sediment density. Alike Gupta et. al. [67], the Hydrate-CASM formulation conceptually divides the sediment void-space into potential void volume $\left(V_{v}\right)$ and available void volume $\left(V_{a}\right)$ (Figure 4$)$. The potential void volume is the space between the mineral grains of the sediment and includes the available void volume for fluid flow and storage and the hydrate volume. 
242 To introduce the densification effect that pore invasion with hydrate has on the mechanical 243 response of the sediment; the Hydrate-CASM uses the available void ratio left after hydrate 244 formation (Eq.13) to derive the mechanical properties of the sediment.

$e_{a_{h}}=e\left(1-S_{h}\right)=e-e_{h}(13)$

247 From where, variations in $\xi$ with hydrate saturation can be derived as:

$248 d \xi=d e_{h}(14)$

249 In addition to the reduction of sediment available void ratio, the presence of hydrate also 250 enhances the sediment stiffness $[16,22,23]$. We represent the stiffening effect of hydrate on 251 the elastic response of the sediment by the following explicit dependency between $\kappa$ and $S_{h}$ :

$252 \kappa_{h}=\kappa \kappa_{r f}$

253 With:

$254 \quad \kappa_{r f}=\left\{\begin{array}{rr}1, & S_{h}=0 \\ 3 S_{h}{ }^{2}-2.68 S_{h}+0.9934, & 0<S_{h} \leq 0.42 \\ 0.397, & S_{h}>0.42\end{array}\right.$

255 Equation 16 is obtained empirically by calibrating the experimental data of three synthetic 256 sediments with hydrate saturations ranging from $24.2 \%$ to $53.1 \%$ (data examined in section 257 4.2). This empirical relation needs validation for other sediments and hydrate saturations 258 outside the range used for its determination.

259 The decrease of $\kappa$ in MHBS has been recently observed in experimental high-pressure 260 oedometer tests [68]. In our formulation the use of $\kappa_{r f}$ compensates for spurious changes of $K$ (Eq. 3a) when reducing the sediment available void ratio with increasing $S_{h}$. If neglecting the hydrate-related stiffening effect suggested in Eq.15, the Hydrate-CASM is still capable of reproducing a close solution to the experimental results (purple line in Figure 5b). However, the use of $\kappa_{h}$ adopted in this work leads to a better fit of the elastic response and the peak strength of synthetic hydrate-bearing sediments subjected to triaxial shear (red line in Figure $5 b)$. 
271

As a result of both the decrease of the host sediment available void ratio and the increase of its stiffness during hydrate formation, a greater isotropic yield stress can be deduced graphically in the $v-\ln \left(p^{\prime}\right)$ space by projecting $e_{a h}$ on the normal consolidation line (NCL) of the host sediment following the $\kappa_{h}$ slope (Figure 5a), so that:

$p_{0_{h}}^{\prime}=\exp \left(\frac{e_{h}}{\lambda-\kappa_{h}}\right) p_{0}^{\prime}\left(\frac{\lambda-\kappa}{\lambda-\kappa_{h}}\right)$

Where changes in $p_{0_{h}}^{\prime}$ are computed through $d p_{0}^{\prime}$, which reads:

$d p_{0}^{\prime}=\frac{\left(1+e_{a h}\right) p_{0}^{\prime}}{\lambda-\kappa} d \varepsilon_{v}^{p}$

\subsubsection{MHBS critical state}

To evaluate the influence of the densification mechanism due to hydrate formation in the critical state of the sediment, Figure $6 \mathrm{~b}$ relates the potential void ratio of the host sediment $(e)$ with the isotropic yield stress predicted after hydrate formation $\left(p_{0 h}^{\prime}\right)$.

Figure 6a shows the procedure to obtain the isotropic yield stress of the MHBS $\left(p_{0 h}^{\prime}\right)$, for which the sediment with hydrate is considered mechanically denser $\left(e_{a h}<e\right)$ and stiffer $\left(\kappa_{h}<\kappa\right)$ than the corresponding host sediment. When relating $p_{0 h}^{\prime}$ with the potential void ratio of the sediment $(e)$, both the NCL and CSL move to the right in the $v-\ln \left(p^{\prime}\right)$ space (Figure $6 \mathrm{~b}$ ). Thus, for a given $S_{h}$ the model predicts a normal consolidation line NCLh that is parallel to that for the host sediment (NCL) and that keeps a vertical distance from the CSLh equal to $\xi_{r}$ (Table 2).

\subsubsection{Hydrate dissociation phenomena}

Several experimental studies [69-74], and field observations [7-9, 13, 14] have demonstrated the impact of hydrate dissociation in the mechanical properties of MHBS. Hydrate dissociation occurs when the P-T and salinity conditions of the system are outside the hydrate stability zone. In the case of hydrate dissociation, the available void ratio of the sediment increases proportionally to the volume of hydrate dissociated, which in turn increases the sediment permeability and reduces its stiffness and strength [22, 75]. Consequently, stress changes and mechanical deformation might be expected during specific conditions of hydrate dissociation. 
This aspect is integrated in the model since equations 13 to $17 \mathrm{~b}$ predict an increase in both $e_{a_{h}}$ and $\kappa_{h}$, as well as a decrease in $p_{0_{h}}^{\prime}$ with decreasing $S_{h}$.

Figures 7 and 8 examine qualitatively the performance of the model in two different scenarios of thermal-induced hydrate dissociation under constant effective stress.

Figure 7 shows the ability of the model at predicting sediment collapse induced by hydrate dissociation after isotropic consolidation. Upon hydrate dissociation, the sediment is assumed to recover the mechanical properties of the host sediment (i.e., NCL and CSL). Then, and as observed by Yoneda's et al. [68] observations, if after the hydrate dissociation the $v-$ $\ln \left(p^{\prime}\right)$ state of the sediment is located in a mechanically inadmissible stress state (point 4 in Figure 7c) the model can predict sediment collapse until reaching a normally consolidated state (point 5 in Figure 7c).

Figure 8 examines the deformation properties of a hydrate-free specimen and a dissociated MHBS during triaxial shear. Initially, both sediments are isotropically consolidated up to $p_{i s o}^{\prime}$ (Figures 8a and 8c). After consolidation, the MHBS is subjected to dissociation under constant effective stress (point 3, Figure 8d), so that the mechanical properties of the host sediment are recovered (i.e., NCL and CSL, Figure 8d). Then, both sediments are sheared under drained conditions. In agreement with experimental observations in synthetic MHBS subjected to dissociation after isotropic consolidation [75], our model predicts a lower failure strength for the MHBS after dissociation than that observed in the host sediment during shear (Figure 8e).

\section{HYDRATE-CASM PERFORMANCE}

Triaxial tests at constant hydrate saturation provide very useful information to understand the influence of hydrate saturation on the mechanical behavior of MHBS. Two sets of stress-strain data from published triaxial tests are used here to evaluate the model performance. The selected experimental data report the mechanical behavior of synthetic MHBS subjected to drained triaxial shear at different confining effective stress, hydrate morphology and saturation. This data have been widely used to calibrate previous mechanical models developed for MHBS, which allows us to compare the model results and validate our formulation. 
Masui et al. [19] conducted several triaxial tests on synthetic MHBS with different hydrate saturation and morphologies. Toyoura sand specimens with slightly different void ratios (Table 3) were used as host sediments for the synthetic formation of hydrate with cementing and porefilling morphologies. Prior to forming hydrate, the host sediments were isotropically consolidated up to $1 \mathrm{MPa}$ of confining effective stress. Then, the ice-seed method and the partial water saturation method were employed to produce hydrates with dominant pore-filling and cementing morphologies, respectively. After hydrate formation, the hydrate-bearing sand specimens were sheared at a constant rate of $0.1 \% \mathrm{~min}^{-1}$ in drained conditions.

The set of critical state parameters characterizing the behavior of pure Toyoura sand (i.e., hydrate-free sediment) (Table 4) have been calibrated here using the stress-strain curve and the volumetric response of the host specimen used for the synthetic formation of cementing hydrate $\left(S_{h}=0 \%\right.$ in Figure 9c). For the calibration process, values adopted in previous publications that also model the mechanical response of Toyoura sand have been used as a reference [e.g., 41, $45,49]$. In addition, the different void ratios of 0.6 and 0.75 reported for the cementing and pore-filling specimens respectively, have also been considered in the simulations (Table 4).

Figure 9 shows the model results for Masui's et al. [19] triaxial tests. Overall, our results are satisfactory if one keeps in mind the simplicity of the model formulation in terms of the number of input parameters required. The Hydrate-CASM successfully captures the trend and magnitude of the mechanical response of MHBS subjected to shear, showing an increase in stiffness, shear strength, and dilatancy with increasing $S_{h}$ (Figures 9c to 9f). The model outputs fit particularly well the volumetric response of the cementing specimens (Figure 9e) as well as the rate of increase observed in the peak strength with $S_{h}$ (Figure 9f). However, they underestimate the maximum deviatoric stress of the cementing specimen with $S_{h}=55.1 \%$ (Figure 9c) and slightly overestimate the maximum deviatoric stress of the pore-filling specimen with $S_{h}=26.4 \%$ (Figure 9d) and the volumetric response of the pore-filling sediment with $S_{h}=40.9 \%$ (Figure 9e).

Previous mechanical models for MHBS that also modelled Masui's et al. [19] experimental data [e.g., 39, 41, 50] assume that the differences in strength and dilatancy observed between 
cementing and pore-filling specimens for a given hydrate saturation are controlled by hydrate morphology. However, Masui et. al. [19] state that if the pore hydrate saturation is the same in both types of specimens (e.g., $S_{h} \approx 40 \%$ in Figures $9 \mathrm{c}$ and $9 \mathrm{~d}$ ), shear strength becomes higher for the specimen with lower void ratio. The similarity between the results from previous models and those obtained with the Hydrate-CASM (Figure 10), which does not consider mechanical contributions related to hydrate morphology, suggests that the different mechanical behavior between cementing and pore-filling specimens can be alternatively reproduced considering the different void ratios reported for each set of the host specimens (Table 3).

\subsection{Modeling of Hyodo's et al. (2013) experimental tests}

Hyodo et al. [21] performed a series of triaxial tests to investigate the mechanical properties and dissociation characteristics of synthetic MHBS. They used an innovative temperature controlled high-pressure apparatus specially developed to reproduce the in-situ conditions expected during gas extraction from hydrates. Three sets of triaxial tests conducted at zero or constant hydrate saturation are used here for the model application. The tests were performed on Toyoura sand with an initial porosity of about $40 \%(e \approx 0.65)$, subjected to confining effective stress of 1, 3 and $5 \mathrm{MPa}$ with different hydrate saturations. The experimental data from the host sediments (i.e., hydrate-free specimens) are used to calibrate the critical state parameters of the model (Table 5) and those from the hydrate-bearing sand are used to examine the model capability at capturing the mechanical effect of $S_{h}$.

Figure 11 shows the simulation of the experimental tests performed by Hyodo et al. [21]. The results show the capability of the Hydrate-CASM at capturing changes in the mechanical response of the host sediment with increasing confining effective stress. For the host sediment confined at $1 \mathrm{MPa}$ the model predicts a moderate softening after a peak and the volumetric strain goes from compressive to slightly dilatant $\left(S_{h}=0 \%\right.$, Figure 11a). With increasing effective stress, the model predicts a gradual transition of this response towards a hardening and a fully contracting behavior, although the maximum deviatoric stress at 3 and $5 \mathrm{MPa}$ are slightly underestimated $\left(S_{h}=0 \%\right.$; Figure $11 \mathrm{c}$ and $\left.11 \mathrm{e}\right)$. The results for the hydrate-bearing sand show, in general, a good agreement with the experimental data, capturing both the trend and magnitude of the stress-strain and volumetric responses of the sediment (Figure 11a, c and 11e) and the $e-\ln \left(p^{\prime}\right)$ paths during triaxial shear (Figure 11b, 11d and 11f). However, the model 
largely overestimated the peak strength for the sediment with $S_{h}=53.7 \%$ tested at $3 \mathrm{MPa}$ (Figure 11c).

The maximum strength of the sediments examined in this section tends to increase almost linearly with hydrate saturation. However, the sediment with $S_{h}=53.7 \%$ does not follow this trend (Figure 12a). Hyodo et al. [21] estimated the hydrate saturation within the sediment based on the stoichiometry of the hydrate formation reaction and assuming that all the methane gas injected converted into hydrate. Several studies have proposed that hydrate and gas can coexist under hydrate stability conditions [76-78]. In particular, Sahoo et al. [79] show experimental evidence in which hydrate formation stops with up to $13 \%$ of gas still on the sediment under favorable pressure, temperature and salinity conditions. Accordingly, we hypothesize that is possible that part of the gas injected into the specimen with $S_{h}=53.7 \%$ could not form hydrate and consequently, the saturation reported could have been slightly overestimated. For comparison purposes, the same test was modelled considering $S_{h}=24.2 \%$, which is a more consistent value within the linear $q_{\max }-S_{h}$ trend observed for the rest of the experimental data (Figure 12a). Considering $S_{h}=24.2 \%$, the Hydrate-CASM reproduces closely the deviatoric stress-axial strain relationship reported experimentally (Figure 12b).

The results presented in this section have been validated against the outputs from three other mechanical models for MHBS [41, 48, 49] (Figure 13). The comparison is satisfactory and shows that, despite the simplicity of the densification mechanism, the Hydrate-CASM performs similarly to models that require more than one hydrate-related empirical parameters in their formulation.

\section{CONCLUSIONS}

The Hydrate-CASM is a new elastoplastic constitutive model developed to simulate the mechanical behavior of MHBS. This model extends the formulation of the CASM model by implementing the subloading surface model and introducing the densification mechanism. Alternatively to bonding or cementing models, the Hydrate-CASM suggests that the greater strength and dilatancy observed in MHBS can be explained by the densification and stiffening effects that pore invasion with hydrate has on the mechanical properties of the sediment. The 
densification mechanism attributes hydrate-related changes in the host sediment available void ratio, swelling line slope and isotropic yield stress to sediment stress-strain changes. Moreover, the flexibility in the shape of the Hydrate-CASM yield function and the use of a non-associated flow rule make our formulation particularly suitable for modelling the behavior of sands, the most likely target deposit for commercial exploitation of hydrates.

Compared to previous models for MHBS, our formulation reduces to one the number of empirical hydrate-dependent parameters required to reasonably capture the mechanical behavior of MHBS. The Hydrate-CASM only requires an empirical hydrate-dependent parameter to express changes in the sediment swelling line slope with hydrate saturation. Reducing to one the number of these parameters is an important advance in mechanical constitutive modeling of MHBS (i) because obtaining them through laboratory tests is challenging, especially if their physical meaning is not well understood, and (ii) because eases the application of the Hydrate-CASM model to a wide range of experimental test conditions.

Robust and well-described published experimental tests have been chosen to calibrate the Hydrate-CASM capabilities at modelling the mechanical behavior of MHBS during triaxial shear. These tests cover the most relevant conditions related to MHBS behavior, including a wide range of hydrate saturations, several hydrate morphologies and confinement stress. In addition, they have been previously used to calibrate other mechanical models developed for MHBS, which allowed us to compare and validate our results. Our simulations evidence the ability of the Hydrate-CASM to predict both stress-strain and the volumetric response of synthetic MHBS subjected to triaxial shear and suggest that quantifying the void ratio and the mechanical response of the host sediment is key to isolate hydrate-related mechanical contributions.

\section{ACKNOWLEDGEMENT}

The authors thank the constructive and thoughtful comments of three anonymous reviewers that have helped to improve this article. Maria De La Fuente was supported by the Graduate School of the National Oceanography Centre Southampton.

\section{REFERENCES}


1. Holder G.D., Kamath, V.A., and S.P. Godbole. The potential of natural gas hydrates as an energy resource, Annual Review of Energy 1984; 9, 427-445.

2. Grauls, D. Gas hydrates: Importance and applications in petroleum exploration. Mar. Pet. Geol. 2001; 18, $519-523$.

3. Collett, T. S. Energy resource potential of natural gas hydrates, AAPG Bull. 2002; 86(11), 1971-1992.

4. Dallimore, S R, and Collett, T S. Summary and implications of the Mallik 2002 Gas Hydrate Production Research Well Program. In Scientific results from the Mallik 2002 Gas Hydrate Production Research Well Program, Mackenzie Delta, Northwest Territories, Canada (eds S. R. Dallimore \& T. S. Collett), , 2005 Bulletin 585. Ottawa, Ontario: Geological Survey of Canada.

5. Ruppel, C. Tapping methane hydrates for unconventional natural gas, Elements 2007; 3, $193-199$.

6. Nagel, N. Compaction and subsidence issues within the petroleum industry: From wilmington to ekofisk and beyond. Physics and Chemistry of the Earth 2001; Part A: Solid Earth and Geodesy 26(1-2), 3-14. 7.

7. Freij-Ayoub, R., Tan, C., Clennell, B., Tohidi, B., and Yang, J. A wellbore stability model for hydrate bearing sediments. Journal of Petroleum Science and Engineering 2007; 57(1-2), 209-220.

8. Yamamoto, K., and Dallimore, S. Aurora-JOGMEC-NRCan Mallik 2006- 2008 Gas Hydrate Research Project Progress. Fire in Ice, Methane Hydrate Newsletter, National Energy Technology Laboratory 2008; 8, $1-20$.

9. Dickens, G. R., O’Neil, J. R., Rea, D. K., and Owen, R. M. Dissociation of oceanic methane hydrate as a cause of the carbon isotope excursion at the end of the Paleocene, Paleoceanography 1995; 19, 965-971.

10. Archer, D. Methane hydrate stability and anthropogenic climate change. Biogeosciences 2007; 4, 521-544.

11. Ruppel, C., and J. W. Pohlman. Climate change and the global carbon cycle: Perspectives and opportunities, Fire in the Ice: Methane Hydrate Newsletter 2008; winter, pp. 5 - 8, Off. of Fossil Energy, Natl. Energy Technol. Lab., U.S. Dep. of Energy, Washington, D. C.

12. Minshull, T. A., Marín-Moreno, H., Armstrong McKay, D. I., and Wilson, P. A. Mechanistic insights into a hydrate contribution to the Paleocene-Eocene carbon cycle perturbation from coupled thermohydraulic simulations. Geophysical Research Letters 2016; 43(16), 8637-8644.

13. Sultan, N., P. Cochonat, J. P. Foucher, and J. Mienert. Effect of gas hydrates melting on seafloor slope instability, Mar. Geol. 2004; 213, 379-401.

14. Pecher, I. a., Henrys, S. a., Ellis, S., Chiswell, S. M. and Kukowski, N. Erosion of the seafloor at the top of the gas hydrate stability zone on the Hikurangi Margin, New Zealand. Geophysical Research Letters 2005; 32(24), 3-6.

15. Paull, C. K., Ussler, W., Dallimore, S. R., Blasco, S. M., Lorenson, T. D., Melling, H., Medioli, B. E., Nixon, F. M. \& McLaughlin, F. A. Origin of pingo-like features on the Beaufort Sea shelf and their possible relationship to decomposing methane gas hydrates. Geophysical Research Letters 2007; 34(1), 1-5.

16. Priest, J. A. A laboratory investigation into the seismic velocities of methane gas hydrate-bearing sand. Journal of Geophysical Research 2005; 110(B4), 1-13.

17. Winters, W., Waite, W., Mason, D., Gilbert, L. and Pecher, I. Methane gas hydrate effect on sediment acoustic and strength properties. Journal of Petroleum Science and Engineering 2007; 56(1-3), 127-135.

18. Priest, J. A., Rees, E. V. L. \& Clayton, C. R. I. Influence of gas hydrate morphology on the seismic velocities of sands. Journal of Geophysical Research 2009; 114(B11), 1-13. 
19. Masui, A., H. Haneda, Y. Ogata, and K. A. The effect of saturation degree of methane hydrate on the shear strength of synthetic methane hydrate sediments, Proceedings of the 5th International Conference on Gas Hydrates, Trondheim, Norway 2005; vol. 2037, pp. 657-663.

20. Miyazaki, K., Masui, A., Sakamoto, Y., Aoki, K., Tenma, N., and Yamaguchi, T. Triaxial compressive properties of artificial methane-hydrate-bearing sediment. Journal of Geophysical Research: Solid Earth $2011 ; 116(6), 1-11$.

21. Hyodo, M., Yoneda, J., Yoshimoto, N., and Nakata, Y. Mechanical and dissociation properties of methane hydrate-bearing sand in deep seabed. Soils and Foundations 2013; 53(2), 299-314.

22. Soga, K., S. L. Lee, M. Y. A. Ng, and A. Klar. Characterisation and engineering properties of methane hydrate soils, Characterization and Engineering Properties of Natural Soils 2006; vol. 4, edited by K. Soga et al., pp. 2591-2642, Taylor and Francis, London, U. K.

23. Waite, W. F., Santamarina, J. C., Cortes, D. D., Dugan, B., Espinoza, D. N., Germaine, et al. Physical Properties of Hydrate-Bearing Sediments. Rev. Geophys 2009; 47, RG4003.

24. Hannegan, D., Todd, R. J., Pritchard, D. M. \& Jonasson, B. Uniquely Applicable to Methane Hydrate Drilling. In: SPE/IADC Underbalanced Technology Conference and Exhibition. Houston, USA 2004.

25. McIver, R. D. Role of naturally occurring gas hydrates in sediment transport. The American Association of Petroleum Geologist Bulletin 1982; 66(6), 789-792.

26. Kayen, R.E., and Lee, H.J. Slope stability in regions of sea-floor gas hydrate; Beaufort Sea continental slope, in Schwab, W.C. 1993.

27. Nixon, M. F., and J. L. H. Grozic. Submarine slope failure due to gas hydrate dissociation: A preliminary quantification. Can. Geotech. J. 2007; 44, 314-325

28. Borowski, W. S. \& Paul, C. K. The Gas Hydrate Detection Problem: Recognition of Shallow-Subbottom Gas Hazards in Deep-Water Areas. In: Off-shore Technology Conference. Houston, USA, 1997: Offshore Technology Conference.

29. Chaouachi, M., Falenty, A., Sell, K., Enzmann, F., Kersten, M., Haberthur, D., and Kuhs, W. Microstructural evolution of gas hydrates in sedimentary matri-ces observed with synchrotron x-ray computed tomographic microscopy. Geochem.Geophy. Geosy. 2015, 16:1711-1722.

30. Sahoo, S. K., Madhusudhan, B. N., Marin-Moreno, H., North, L. J., Ahmed, S., Falcon-Suarez, I., and Best, A. Laboratory insights into the effect of sediment-hosted methane hydrate morphology on elastic wave velocity from time lapse 4D synchrotron X-ray computed tomography. Geochemistry, Geophysics, Geosystems. 2018, 19(11):4502-4521.

31. Sell, K., Saenger, H., Quintal, B., and Enzmann, F., K. M. Digital lab of hydrate-bearing sediments: Determination of effective elastic properties on the microscale. European Geosciences Union - General Assembly 2017

32. Pinkert, S. Rowe's Stress-Dilatancy Theory for Hydrate-Bearing Sand. International Journal of Geomechanics 2016; 17(1), 6016008.

33. Pinkert, S. The lack of true cohesion in hydrate-bearing sands. Granular Matter. 2017; 19. 10.1007/s10035017-0742-5.

34. Pinkert, S., and Grozic, J. L. H. Experimental verification of a prediction model for hydrate bearing sand. Journal of Geophysical Research: Solid Earth 2016; (October). 
35. Klar, A., Soga, K., and Ng, M. Y. a. Coupled deformation-flow analysis for methane hydrate extraction. Géotechnique 2010; 60(10), 765-776.

36. Jung, J. W., Santamarina, J. C., and Soga, K. Stress-strain response of hydrate-bearing sands: Numerical study using discrete element method simulations. Journal of Geophysical Research: Solid Earth 2012;117(4), $1-12$.

37. Pinkert, S., and Grozic, J. L. H. Prediction of the mechanical response of hydrate-bearing sands, Journal of Geophysical Research: Solid Earth 2014; 4695-4707.

38. Pinkert, S., Grozic, J. L. H., and Priest, J. A. Strain-Softening Model for Hydrate-Bearing Sands. International Journal of Geomechanics 2015, 15(6), 1-6.

39. Uchida, S., Soga, K., and Yamamoto, K. Critical state soil constitutive model for methane hydrate soil, Journal of Geophysical Research: Solid Earth 2012, 117(B3).

40. Sánchez, M., and Gai, X. Geomechanical and numerical modeling of gas hydrate sediments. Energy Geotechnics 2016, 19-24.

41. Sánchez, M., Gai, X., and Santamarina, J. C. A constitutive mechanical model for gas hydrate bearing sediments incorporating inelastic mechanisms. Computers and Geotechnics 2017; 84, 28-46.

42. Sultan, N., and Garziglia, S. Geomechanical constitutive modelling of gas-hydrate bearing sediments. The 7th International Conference on Gas Hydrates, (ICGH) 2011.

43. De La Fuente, M., Vaunat, J., and Marín-Moreno, H. Composite model to reproduce the mechanical behaviour of Methane Hydrate Bearing Sediments. Energy Geotechnics 2016; 483-489.

44. Jiang, M., Zhu, F., Liu, F., and Utili, S. (2014). A bond contact model for methane hydrate-bearing sediments with interparticle cementation. International Journal for Numerical and Analytical Methods in Geomechanics 2014; 38(17), 1823-1854.

45. Lin, J.S., Seol, Y. and Choi, J. H. An SMP critical state model for methane hydrate-bearing sands. International Journal for Numerical and Analytical Methods in Geomechanics 2015; 32(9), 969-987.

46. Yu, H. S. CASM: a unified state parameter model for clay and sand. International Journal for Numerical and Analytical Methods in Geomechanics 1998; 22(8), 621-653.

47. Hashiguchi, K. Subloading surface model in unconventional plasticity. Int. J. Solids Struct. 1989; 25(8), $917-$ 945.

48. Hyodo, M., Nakata, Y., and Yoshimoto, N. Challenge for methane hydrate production by geotechnical engineering. Proceeding of the 15th Asian Regional Conference on Soil Mechanics and Geotechnical Engineering 2016; 62-75.

49. Uchida, S., Xie, X.-G. and Leung, Y.F. Role of critical state framework in understanding geomechanical behaviour of methane hydrate-bearing sediments, Journal of Geophysical Research 2016; 121(8), 5580-5595

50. Yan, R., and Wei, C. Constitutive Model for Gas Hydrate-Bearing Soils Considering Hydrate Occurrence Habits. International Journal of Geomechanics 2017; 17(8), 4017032.

51. Boswell R, Collett TS. Current perspectives on gas hydrate resources. Energy \& Environmental Science 2011; 4:1206-1215.

52. Been, K. and Jefferies, M. G.. A state parameter for sands. Géotechnique 1985, 35(2), 99-112.

53. Graham, J., Crooks, J. H. A., and Bell, A. L Time effects on the stress-strain behaviour of natural soft clays. Geotechnique. 1983; 33(3),327-340 
54. Lade, B. P. V, and Nelson, R. B. Non-Associated flow and stability of granular materials. J. Eng. Mech,1988; 113(9), 1302-1318.

55. Roscoe, K. H., A. N. Schofield, and C. P. Wroth. On the yielding of soils, Geotechnique 1958, 8(1), 22-53.

56. Roscoe, K. H., and J. B. Burland. On the generalized stress-strain behaviour of wet clays, in Engineering Plasticity. Edited by J. Heyman and F. A. Leckie 1968, Pp. 535-609, Cambridge Univ. Press, Cambridge, England.

57. Nova, R. and Wood, D. M. An experimental program to define yield function for sand, Soils and Foundations 1978, 18(4),77-86.

58. Chandler, H. W. A plasticity theory without Drucker's postulate for granular materials. J. Mech. Phys. Solids $1985,33,215-226$.

59. Rowe, P. W. The stress-dilatancy relation for static equilibrium of an assembly of particles in contact. Proc. Roy. Soc. 1962; 267, 500-527.

60. Jardine, R. J. Some observations on the kinematic nature of soil stiffness. Soils Found. 1992; 32(2), 111-124.

61. Mitchell, J. K., and Soga K. Fundamentals of Soil Behaviour. John Wiley, Hoboken, N.J. 2005.

62. González, N. Development of a family of constitutive models for geotechnical applications. PhD thesis, Polytechnic University of Catalonia, Barcelona (Spain), (May) 2011.

63. Vialle, S. and Vanorio, T. Laboratory measurements of elastic properties of carbonate rocks during injection of reactive CO2-saturated water. Geophysical Research Letters 2011; 38. L01302

64. Nygaard, R., Bjørlykke, K., Høeg, K., Hareland, G. The effect of diagenesis on stress-strain behavior and acoustic velocities in sandstones. Proceedings of the 1st Canada-US Rock Mechanics Symposium - Rock Mechanics Meeting Society's Challenges and Demands 2007.

65. Pinyol Puigmartí, NM., Vaunat, J., Alonso Pérez de Agreda, E. A constitutive model for soft clayey rocks that includes weathering effects. Geotechnique 2007;57 (2):137-51.

66. Chagneau, A., Claret, F., Enzmann, F., Kersten, M, Heck, S., et al.. Mineral precipitation-induced porosity reduction and its effect on transport parameters in diffusion-controlled porous media. Geochemical Transactions, Chemistry Central, 2015, 16 (1), 16 p.

67. Gupta, S., Helmig, R. and Wohlmuth, B. Non-isothermal, multi-phase, multi-component flows through deformable methane hydrate reservoirs. Computational Geosciences. 2015; 19. 1063-1088. 10.1007/s10596015-9520-9.

68. Yoneda, J., Oshima, M., Kida, M., Kato, A., Konno, Y., Jin, Y., Tenma, N. Consolidation and hardening behavior of hydrate-bearing pressure-core sediments recovered from the Krishna-Godavari Basin, offshore India, Marine and Petroleum Geology. 2018, ISSN 0264-8172.

69. Masui, A., H. Haneda, Y. Ogata, and K. A. Mechanical properties of sandy sediment containing marine gas hydrates in deep sea offshore Japan survey drilling in Nankai Trough. In Proceedings of Seventh ISOPE Ocean Mining Symposium, pp. 53-56, International Society of Offshore and Polar Engineers 2007, Lisbon, Portugal.

70. Lu, W., I. M. Chou, and R. C. Burruss. Determination of methane concentrations in water in equilibrium with sI methane hydrate in the absence of a vapor phase by in situ Raman spectroscopy. Geochim. Cosmochim. Acta $2008 ; 72,412-422$. 
71. Lee, J. Y., Santamarina, J. C., and Ruppel, C. Volume change associated with formation and dissociation of hydrate in sediment. Geochemistry, Geophysics, Geosystems 2010, 11(3).

72. Hyodo, M., Kajiyama S., Yoshimoto, N., Nakata, Y. Triaxial behaviour of methane hydrate bearing sand. Proceedings of 10th Int. ISOPE Ocean Mining \& Gas Hydrate Symposium OMS-2013, Szczecin, Poland, 2014; 126-134.

73. Santamarina, J.C.; Dai, S.; Terzariol, M.; Jang, J.; Waite, W.F.; Winters, W.J.; Nagao, J.; Yoneda, J.; Konno, Y.; Fujii, T.; et al. Hydro-bio-geomechanical properties of hydrate-bearing sediments from Nankai Trough. Mar. Pet. Geol. 2015; 66, 1-17.

74. Song, Y.C.; Zhu, Y.M.; Liu, W.G.; Li, Y.H.; Lu, Y.; Shen, Z.T. The effects of methane hydrate dissociation at different temperatures on the stability of porous sediments. Journal of Petroleum Science and Engineering 2016; 147(May), 77-86.

75. Hyodo, M., Li, Y., Yoneda, J., Nakata, Y., Yoshimoto, N., Nishimura, A. Effects of dissociation on the shear strength and deformation behavior of methane hydrate-bearing sediments, Marine and Petroleum Geology. 2014, Volume 51, Pages 52-62, ISSN 0264-8172.

76. Milkov, A. V. Global estimates of hydrate-bound gas in marine sediments: how much is really out there? Earth-Sci. Rev. 2004; 66, 183- 197.

77. Darnell, K. N., and P. B. Flemings. Transient seafloor venting on continental slopes from warming-induced methane hydrate dissociation. Geophys. Res. Lett. 2015; 42, 10765-10772.

78. Goswami, B. K., K. A. Weitemeyer, T. A. Minshull, M. C. Sinha, G. K. Westbrook, A. Chabert, T. J. Henstock, and S. K. A joint electromagnetic and seismic study of an active pockmark within the hydrate stability field at the Vestnesa Ridge, West Svalbard margin. J. Geophys. Res. Solid Earth 2015; 120, 67976822.

79. Sahoo, S., Marín-Moreno, H., North, L., Falcon-Suarez, I. Bn, M., Best, A. and Minshull, T. Presence and Consequences of Coexisting Methane Gas With Hydrate Under Two Phase Water-Hydrate Stability Conditions. Journal of Geophysical Research: Solid Earth.2018; 10.1029/2018JB015598. 
Table 1: Notable mechanical models for MHBS considering hydrate-bonding effect.

\begin{tabular}{|c|c|}
\hline Model reference & Hydrate-bonding modelling strategy \\
\hline $\begin{array}{l}\text { Klar et al. [35]; Jung et al. [36]; Pinkert and } \\
\text { Grozic, [37]; Pinkert et al. [38] }\end{array}$ & Additional cohesion constituent in the failure criteria \\
\hline $\begin{array}{l}\text { Uchida et al. [39]; Sánchez and Gai [40]; } \\
\text { Sánchez et al. [41]. }\end{array}$ & $\begin{array}{l}\text { Enlargement of the yield surface by cohesion and } \\
\text { dilatation }\end{array}$ \\
\hline Sultan and Garziglia et al. [42] & $\begin{array}{l}\text { Impediment of the normal consolidation of the sediment } \\
\text { and enlargement of the yield surface }\end{array}$ \\
\hline \multirow[t]{2}{*}{$\begin{array}{c}\text { Sánchez and Gai [40]; Sánchez et al. } \\
\text { [41].De La Fuente et al. [43] }\end{array}$} & $\begin{array}{l}\text { Stress-strain partition between hydrate and matrix in a } \\
\text { bonding damage framework (BDM) }\end{array}$ \\
\hline & $\begin{array}{c}\text { Attribution of physical bonding properties in discrete } \\
\text { element methods (DEM) }\end{array}$ \\
\hline Lin et al. [45] & $\begin{array}{c}\text { Expansion of the failure envelope in a spatially } \\
\text { mobilized plane (SMP) model }\end{array}$ \\
\hline
\end{tabular}

656

657

658

659

660

661

662

663

664

665

666

667 
670 the hydrate-free parameters $e, v, p_{0}$ and $\kappa$ when $S_{h}=0$.

\begin{tabular}{|c|c|c|}
\hline \multicolumn{2}{|c|}{ Model parameters } & \multirow[t]{2}{*}{ Description } \\
\hline \multirow{10}{*}{ Stress } & $P_{p}$ & \\
\hline & $\sigma$ & Cauchy total stress tensor \\
\hline & $\mathbf{I}$ & Identity matrix \\
\hline & $\sigma^{\prime}$ & Cauchy effective stress tensor, $\boldsymbol{\sigma}^{\prime}=\boldsymbol{\sigma}-P_{p} \mathbf{I}$ \\
\hline & $\sigma_{c}$ & Confining total stress \\
\hline & $\sigma_{c}^{\prime}$ & Confining effective stress, $\boldsymbol{\sigma}^{\prime}{ }_{\boldsymbol{c}}=\boldsymbol{\sigma}_{\boldsymbol{c}}-P_{p}$ \\
\hline & $p$ & Mean stress, $p=1 / 3\left(\sigma_{1}+\sigma_{2}+\sigma_{3}\right)$ \\
\hline & $q$ & Deviatoric stress, $q=\sigma_{1}-\sigma_{3}$ \\
\hline & $p^{\prime}$ & Mean effective stress, $p^{\prime}=p-P_{p}$ \\
\hline & $\eta$ & Stress ratio $\eta=q / p^{\prime}$ \\
\hline \multirow{5}{*}{ Strain } & $\varepsilon$ & Total infinitesimal strain tensor \\
\hline & $\varepsilon^{e}$ & Elastic strain tensor \\
\hline & $\left|d \varepsilon^{p}\right|$ & Norm of the incremental plastic strain vector \\
\hline & $\varepsilon_{v}^{p}$ & Plastic volumetric strain, $\varepsilon_{v}^{p}=\varepsilon_{1}^{p}+\varepsilon_{2}^{p}+\varepsilon_{3}^{p}$ \\
\hline & $\varepsilon_{q}^{p}$ & Plastic deviatoric strain, $\varepsilon_{q}^{p}=\frac{2}{3}\left(\varepsilon_{1}^{p}-\varepsilon_{3}^{p}\right)$ \\
\hline \multirow{11}{*}{$\begin{array}{c}\text { Volumetric } \\
\text { ratios }\end{array}$} & $V_{t}$ & Total volume \\
\hline & $V_{s}$ & Volume of mineral grains \\
\hline & $V_{h}$ & Volume of hydrate \\
\hline & $V_{v}$ & Potential void volume, $V_{v}=V_{t}-V_{s}$ \\
\hline & $V_{a}$ & Available void volume, $V_{a}=V_{v}-V_{h}$ \\
\hline & $e$ & Void ratio of the host sediment, $e=V_{v} / V_{s}$ \\
\hline & $S_{h}$ & Hydrate saturation, $S_{h}=V_{h} / V_{v}$ \\
\hline & $e_{h}$ & Hydrate ratio, $e_{h}=V_{h} / V_{s}=S_{h} e$ \\
\hline & $e_{a_{h}}$ & Available void ratio of the hydrate-bearing sediment, $e_{a_{h}}=e\left(1-S_{h}\right)$ \\
\hline & $v$ & Specific volume, $v=1+e$ \\
\hline & $v_{h}$ & Hydrate-CASM equivalent specific volume, $v_{h}=v-e_{h}$ \\
\hline \multirow{6}{*}{$\begin{array}{l}\text { Critical state } \\
\text { parameters }\end{array}$} & $\lambda$ & Slope of the normal compression and critical state lines in the $v-\ln \left(p^{\prime}\right)$ space \\
\hline & $M$ & Critical state stress ratio: slope of critical state line in the $p^{\prime}-q$ space \\
\hline & $p_{0}$ & Isotropic yield stress of the host sediment \\
\hline & $p_{0_{h}}$ & Isotropic yield stress of the hydrate-bearing sediment \\
\hline & $p_{x}^{\prime}$ & Mean effective stress at critical state \\
\hline & $\Gamma$ & Specific volume at critical state with $p^{\prime}$ of $1 \mathrm{KPa}$ \\
\hline \multirow{6}{*}{$\begin{array}{c}\text { Elastic } \\
\text { parameters }\end{array}$} & $\kappa$ & Host sediment swelling (reloading-unloading) line slope \\
\hline & $\kappa_{h}$ & MHBS swelling (reloading-unloading) line slope \\
\hline & $v$ & Poisson's ratio \\
\hline & $K$ & Elastic bulk modulus \\
\hline & $G$ & Elastic shear modulus \\
\hline & $D^{e}$ & Elastic stiffness tensor \\
\hline \multirow{4}{*}{$\begin{array}{c}\text { CASM } \\
\text { parameters }\end{array}$} & $n$ & Stress-state coefficient: yield surface shape parameter \\
\hline & $r$ & Spacing ratio, $r=p_{0}^{\prime} / p_{x}^{\prime}$ \\
\hline & $\xi$ & State parameter \\
\hline & $\xi_{r}$ & Reference state parameter, $\xi_{r}=(\lambda-\kappa) \ln r$ \\
\hline
\end{tabular}




\begin{tabular}{ccl}
\hline Subloading & $p_{0_{s}}$ & Isotropic yield stress of the subloading surface \\
parameters & $R$ & Subloading surface ratio, $R=p_{0_{S}} / p_{0}$ \\
& $u$ & Subloading parameter controlling plastic deformations before yielding \\
\hline \multirow{2}{*}{ Plastic } & $\varphi$ & Size parameter \\
parameters & $H$ & Vector of hardening (2 components: $p_{0_{h}}$ and $\left.R\right)$ \\
& $\lambda^{p}$ & Plastic multiplier \\
\hline Empirical & \multirow{2}{*}{$\begin{array}{l}\text { parameters } \\
\text { parf }\end{array}$} & Swelling line reduction factor \\
\hline
\end{tabular}

671

672

673

674

675

676

677

678

679

680

681

682

683

684

685

686

687

688

689

690 
691 Table 3. Physical properties of Toyoura sand specimens used in Masui et al. [19] as host 692 sediment for the synthesis of cementing and pore-filling hydrates.

Host sediment physical properties

\begin{tabular}{lcc}
\hline & Cementing specimens & Pore-filling specimens \\
\hline Diameter/height $(\mathrm{mm})$ & $50 / 100$ & $50 / 100$ \\
Density $\left(\mathrm{g} / \mathrm{cm}^{3}\right)$ & $1.74-1.92$ & $1.77-1.78$ \\
Void ratio & $0.57-0.63$ & $0.73-0.75$ \\
\hline
\end{tabular}

693

694

695

696

697

698

699

700

701

702

703

704

705

706

707

708

709

710

711

712

713

714 
715 Table 4. Host sediment input parameters for modeling Masui et al. [19] triaxial tests.

\begin{tabular}{cccccccccc}
\hline \multicolumn{7}{c}{ Host sediment input parameters } \\
\hline$e$ & $\lambda$ & $M$ & $p_{0}^{\prime}(M P a)$ & $\kappa$ & $v$ & $n$ & $r$ & $p_{0_{s}}^{\prime}(M P a)$ & $u$ \\
\hline \multirow{2}{*}{0.6} & 0.22 & 1.17 & 12 & 0.015 & 0.1 & 2.5 & 1.7 & 3.5 & 20 \\
\hline & & & \multicolumn{7}{c}{ Cementing specimens } \\
0.75 & 0.22 & 1.17 & 5.3 & 0.015 & 0.1 & 2.5 & 1.7 & 3 & 20 \\
\hline
\end{tabular}

716

717

718

719

720

721

722

723

724

725

726

727

728

729

730

731

732

733

734

735

736 
737 Table 5. Host sediment input parameters for modelling Hyodo's et al. [21] triaxial tests at 1, 3 738 and $5 \mathrm{MPa}$ of confining effective stress.

\begin{tabular}{cccccccccc}
\hline \multicolumn{10}{c}{ Host sediment input parameters } \\
\hline$e$ & $\lambda$ & $M$ & $p_{0}^{\prime}(M P a)$ & $\kappa$ & $v$ & $n$ & $r$ & $p_{0_{s}}^{\prime}(M P a)$ & $u$ \\
\hline 0.65 & 0.22 & 1.32 & 9 & 0.015 & 0.1 & 4 & 2.5 & 5.6 & 50
\end{tabular}

739 